\title{
RGS16, a novel p53 and pRb cross-talk candidate inhibits migration and invasion of pancreatic cancer cells
}

\author{
Miranda B. Carper ${ }^{1,2}$, James Denvir ${ }^{2}$, Goran Boskovic ${ }^{2}$, Donald A. Primerano ${ }^{2}$ and \\ Pier Paolo Claudio ${ }^{1,2,3}$ \\ ${ }^{1}$ McKown Translational Genomic Research Institute, Joan C. Edwards School of Medicine, Marshall University, Huntington, \\ WV, USA \\ ${ }^{2}$ Department of Biochemistry and Microbiology, Joan C. Edwards School of Medicine, Marshall University, Huntington, WV, \\ USA \\ ${ }^{3}$ Department of Surgery, Joan C. Edwards School of Medicine, Marshall University, Huntington, WV, USA \\ Correspondence to: Pier Paolo Claudio, email: claudiop@marshall.edu
}

Keywords: p53, pRb, RGS16, EGF, migration, pancreatic cancer

Received: October 8, $2014 \quad$ Accepted: November 26, $2014 \quad$ Published: November 27, 2014

This is an open-access article distributed under the terms of the Creative Commons Attribution License, which permits unrestricted use, distribution, and reproduction in any medium, provided the original author and source are credited.

\section{ABSTRACT}

Data collected since the discovery of p53 and pRb/RB1 suggests these tumor suppressors cooperate to inhibit tumor progression. Patients who have mutations in both p53 and RB1 genes have increased tumor reoccurrence and decreased survival compared to patients with only one tumor suppressor gene inactivated. It remains unclear how p53 and pRb cooperate toward inhibiting tumorigenesis. Using RNA expression profiling we identified 179 p53 and pRb cross-talk candidates in normal lung fibroblasts (WI38) cells exogenously coexpressing p53 and pRb. Regulator of G protein signaling 16 (RGS16) was among the p53 and pRb cross-talk candidates and has been implicated in inhibiting activation of several oncogenic pathways associated with proliferation, migration, and invasion of cancer cells.

RGS16 has been found to be downregulated in pancreatic cancer patients with metastases compared to patients without metastasis. Expression of RGS16 mRNA was decreased in the pancreatic cancer cell lines tested compared to control. Expression of RGS16 inhibited migration of the BXPC-3 and ASPC-1 but not PANC-1 cells and inhibited invasion of BXPC-3 and AsPC-1 cells with no impact on cell viability. We have identified for the first time p53 and pRb cross-talk candidates and a role for RGS16 to inhibit pancreatic cancer migration and invasion.

\section{INTRODUCTION}

The $\mathrm{p} 53$ and $\mathrm{pRb}$ tumor suppressors are two signaling pathways that are frequently altered during cancer progression. Mutations that disrupt the p53 and $\mathrm{pRb}$ pathways can occur in the gene sequences or in their upstream regulators and/or downstream effectors. Results of studies have found that both tumor suppressor genes are inactivated in a variety of malignancies including osteosarcoma, small cell lung, breast, and bladder carcinomas [1-4]. Furthermore, alterations in expression or activity of proteins involved in $\mathrm{p} 53$ and $\mathrm{pRb}$ signaling pathways have been identified in retinoblastoma and cancers of the pancreas, colon, and head and neck among others [5-8]. The large number of cancers that have defects in the $\mathrm{p} 53$ and $\mathrm{pRb}$ pathways demonstrates the importance of these genes in preventing cancer development and progression.

Existing data suggests that $\mathrm{p} 53$ and $\mathrm{pRb}$ cooperate to prevent tumor progression. Examples of this cooperative interaction have been shown by various studies using human primary cancer samples and mouse models. Patients who have mutations in both $\mathrm{p} 53$ and $R B 1$ genes have increased tumor recurrence and decreased survival compared to patients with a mutation in either p53 or $R B 1[1,9,10]$. A study conducted in mice found that p53 null mice who were also heterozygous for $R B 1$ were susceptible to developing more tumors than mice with single mutations; i.e. heterozygous p53 or $R B 1$ null or p53 null mice [4]. In another study, mice with conditional 
inactivation of both $\mathrm{p} 53$ and $R B 1$ in prostate epithelium developed highly metastatic tumors and had decreased survival time compared to mice with single p53 or $R B 1$ inactivation [11]. The accumulated evidence suggests $\mathrm{p} 53$ and $R B 1$ gene products have cooperative or synergistic effects for cancer suppression.

Considering the network of communication that exists within a cell, the rate of mutation of p53 and $R B 1$, and the cellular processes these two proteins regulate, a natural hypothesis is that these two genes and respective gene products cross-communicate in order to determine cellular fate and prevent carcinogenesis. In fact, there are known examples of genes and proteins that are involved in the convergent signaling between the p53 and pRb pathways; such as Hdm2, p21, E2F-1 and the INK4a locus (reviewed in [9, 12-14]). Although several proteins that are involved in the p53 and pRb pathways have been identified, the full extent in which these two tumor suppressors interact along their pathway to regulate cellular fate is still unknown. To identify downstream targets of both $\mathrm{p} 53$ and $\mathrm{pRb}$ regulation and to elucidate mechanisms of p53 and pRb cross-talk, we coexpressed p53 and $\mathrm{pRb}$ in normal human lung fibroblast cells (WI38) and used RNA expression profiling to identify up- or down-regulated genes. We identified Regulator of G protein Signaling 16 (RGS16) as a p53 and pRb crosstalk candidate.

RGS16, previously found to be induced by doxorubicin in cells expressing wild-type p53, belongs to a large family of proteins that plays a role in swiftly shutting down G protein-coupled receptor (GPCR) signaling pathways $[15,16]$. RGS16 is a GTPase activating protein (GAP) that aids GTPase activity of the $\alpha$-subunit of $\mathrm{G}$ proteins associated with G-protein coupled receptors (GPCR). RGS16 has been implicated in negatively regulating the MAPK, AKT/PI3K, RhoA, and SDF-1/CXCR4 oncogene pathways in normal or cancer cell lines [15, 17-19]. These oncogene pathways have been implicated in cancer progression processes (such as proliferation, survival, chemoresistance, migration, invasion, and metastasis in a variety of malignancies including pancreatic cancer [20-24]. Recently, evidence has demonstrated a role of RGS16 in cancer signaling. RGS16 locus is a site of genomic instability in $(50 \%$ of 222) primary breast tumors and knockdown of RGS16 in breast cancer cell lines increases Epidermal Growth Factor (EGF) and Fetal Bovine Serum (FBS) initiated proliferation [19, 25]. A previous report using tissue microarray analysis revealed decreased expression of Regulator of G-protein signaling 16 (RGS16) in pancreatic tumors with lymph-node metastases compared to nonmetastasized pancreatic cancer and this loss was associated with decreased patient survival [26]. Based upon the link of RGS16 regulating several oncogenic pathways and the decreased expression of RGS16 in metastasized pancreatic cancer, we chose to further study the function of RGS16 in pancreatic cancer in order to identify the role it has in the p53 and pRb signaling pathways. Currently, RGS16 has not been linked with inhibition of cancer cell metastasis nor has its function been investigated to understand it's downregulation in metastasized pancreatic cancer. The majority of patients newly diagnosed with pancreatic cancer present with highly progressed and/or metastatic cancer that is resistant to treatment $[27,28]$. Due to the late stage of diagnosis and the aggressive nature of this disease, less than $20 \%$ of pancreatic cancer patients are eligible for the potentially curative surgery $[28,29]$. Therefore, there is a great need for more effective drugs aimed at treating or preventing metastatic pancreatic cancer. Pancreatic cancer is associated with p53 mutations and p16 (pRb activator) deletions resulting in the crippling of both the $\mathrm{p} 53$ and $\mathrm{pRb}$ pathways. By investigating the p53 and pRb cross-talk and the role of RGS16 in pancreatic cancer cell migration, we have uncovered a novel regulator of metastasis processes that could be a future target in developing treatments for metastatic pancreatic cancer.

\section{RESULTS}

\section{Identification of p53 and pRb cross-talk candidates in WI38 cells following coexpression of $\mathrm{p53}$ and/or pRb}

Studies have shown that p53 and pRb cooperate to prevent tumorigenesis. Currently, the molecules that function in the p53 and pRb cross-talk pathway to regulate cellular fate are not known thus expression profiling by microarray was performed to find genes coregulated by p53 and pRb. Normal human lung WI38 fibroblast cells were transduced with adenoviral vectors expressing the p53 and/or RB1 genes under the control of a cytomegalovirus (CMV) promoter. The WI38 cell line was used because it is from non-cancerous tissue and lacks mutations or viral transformations that could disrupt the p53 and pRb pathways. Four experimental conditions were used in which WI38 cells were transduced with adenovirus vector control (cond. 1, Adenoviral CMV-vector control, Ad.CMV.p53 (cond. 2), Ad.CMV.pRb (cond. 3), or both Ad.CMV.p53 and Ad.CMV.pRb (cond. 4). RNA and protein from WI38 cells was collected 48 hours after adenoviral infection. Immunoblots verified increased expression of p53 (fold change compared to Ad.CMV control $=2.80,1.54$, and 2.77) and/or hypophosphorylated (active form) $\mathrm{pRb}$ (hypophosphorylated/total $\mathrm{pRb}$ fold change compared to Ad.CMV control $=0.94,5.48,5.02$ ) in the WI38 cells treated with adenoviruses containing p53, $\mathrm{pRb}$, or both $\mathrm{p} 53$ and $\mathrm{pRb}$ respectively (Figure $1 \mathrm{~A}$ and 1B). Fold change values for p53 and hypophosphorylated $\mathrm{pRb}$ coincided with previously reported results in experiments that activated endogenous p53 and pRb 
Table 1. Fold Change of p53 and pRb common gene set cross-talk candidates.

\begin{tabular}{|c|c|c|c|c|}
\hline Gene Symbol & Name & $\begin{array}{l}\text { FC- } \\
\text { p53 }\end{array}$ & FC-Rb & $\begin{array}{l}\text { FC- } \\
\text { p53+Rb }\end{array}$ \\
\hline LOC387763 & hypothetical LOC387763 & 30.62 & 159.25 & 297.07 \\
\hline $\begin{array}{l}\text { A_24_p77581 } \\
2\end{array}$ & Unknown & 15.65 & 199.36 & 252.80 \\
\hline RGS16 & Regulator of G-protein signaling 16 & 18.84 & 30.82 & 149.75 \\
\hline AREG & Amphiregulin & 8.15 & 46.41 & 81.91 \\
\hline CCL3 & Chemokine (c-c motif ligand 3) & 3.78 & 8.18 & 56.12 \\
\hline TNFSF15 & $\begin{array}{l}\text { Tumor necrosis factor (ligand) superfamily, member } \\
15\end{array}$ & 10.68 & 69.61 & 53.34 \\
\hline IL-1B & Interleukin-1 beta & 4.82 & 22.53 & 43.79 \\
\hline OLFM2 & Olfactomedin 2 & 10.60 & 37.76 & 27.31 \\
\hline NR4A1 & Nuclear receptor subfamily 4 group A member 1 & 11.56 & 20.73 & 27.08 \\
\hline POSTN & Periostin & 2.91 & 21.051 & 25.66 \\
\hline D4S234e & $\begin{array}{l}\text { D4S234e (NSG1; neuron specific gene family } \\
\text { member 1) }\end{array}$ & 21.20 & 7.86 & 22.06 \\
\hline IL-6 & Interleukin-6 & 6.04 & 12.37 & 21.99 \\
\hline DMN & Desmuslin & 4.57 & 27.42 & 21.25 \\
\hline EPPK1 & Epiplakin & 32.06 & 8.27 & 20.04 \\
\hline IQSEC3 & IQ motif and Sec7 domain 3 & 7.29 & 20.37 & 19.95 \\
\hline PLAC2 & Placenta specific 2 & 21.60 & 4.63 & 19.00 \\
\hline L3MBTL2 & Lethal(3)malignant brain tumor-like protein 2 & 18.33 & 11.82 & 16.00 \\
\hline LHX6 & LIM homeobox 6 & 10.11 & 7.11 & 15.15 \\
\hline AKR1B10 & Aldo-keto reductase family 1 member B10 & 11.61 & 13.92 & 13.30 \\
\hline RRAD & Ras associated with diabetes & 5.98 & 7.80 & 12.61 \\
\hline c10orf58 & chromosome 10 open reading frame 58 & 4.86 & 9.20 & 11.74 \\
\hline BCL2L11 & Bcl2-like 11 (apoptosis facilitator) & 9.58 & 6.50 & 11.34 \\
\hline COL7A1 & Collagen, type VII, alpha 1 & 5.97 & 10.65 & 10.94 \\
\hline JUP & Junction plakoglobin & 7.60 & 16.61 & 9.92 \\
\hline VCAN & Versican proteoglycan & 5.61 & 9.17 & 9.73 \\
\hline CRISPLD2 & Cystein-rich secretory protein 11 & 10.11 & 5.38 & 9.55 \\
\hline STOX2 & Storkhead-box 2 & 14.48 & 8.70 & 9.33 \\
\hline BTG-2 & B-cell translocation gene 2 & 3.85 & 5.07 & 7.46 \\
\hline P2RY2 & purinergic receptor P2Y, G-protein coupled, 2 & 2.38 & 19.53 & 6.91 \\
\hline TSKU & Tsukusi,small leucine rich proteoglycan & 5.28 & 5.42 & 5.97 \\
\hline C4B & Complement component 4B & 3.38 & 7.64 & 2.22 \\
\hline RTN4R & Reticulon 4 receptor & 8.01 & 6.19 & $\mathrm{~N} / \mathrm{A}$ \\
\hline STAT4 & Signal transducer and activator of transcription 4 & 5.98 & 7.80 & N/A \\
\hline AK124344 & cDNA FLJ42353 fis, clone UTERU2007520 & 5.21 & 7.13 & $\mathrm{~N} / \mathrm{A}$ \\
\hline KLHL20 & Kelch like 20 & 4.88 & 4.46 & N/A \\
\hline NOTCH3 & Notch homolog 3 & 4.68 & 3.96 & N/A \\
\hline KSR1 & Kinase suppressor of RAS & 3.86 & 4.08 & $N / A$ \\
\hline GDF15 & Growth/differentiation factor 15 & 3.24 & 3.40 & $\mathrm{~N} / \mathrm{A}$ \\
\hline LOC654346 & similar to galectin 9 short isoform (LOC654346) & 2.81 & 4.77 & $\mathrm{~N} / \mathrm{A}$ \\
\hline
\end{tabular}

[30, 31]. Microarray data from the adenovirus vector control (empty vector with CMV promoter) was used as a reference to determine genes that were differentially expressed as a consequence of $\mathrm{p} 53, \mathrm{pRb}$, and $\mathrm{p} 53+\mathrm{pRb}$ expression. Analysis of the microarray data identified 294p53, 650-pRb, and 514-p53 + pRb differentially expressed genes (Figure 1C; see Supplementary Document 1 for full list of differentially expressed genes). Of the differentially expressed genes, 294/294 genes were upregulated in cells with p53 expression, 427/650 genes were upregulated in cells with pRb expression, and 319/514 genes were up- regulated in cells with p53 + pRb coexpression (Figure $1 C)$. Consistent with protein measurements, increased expression of $\mathrm{p} 53$ and/or $R B 1$ mRNAs were also found in the appropriate groups (Supplementary Document 1).

A Venn diagram shows the number of differentially expressed genes shared between the experimental groups (Figure 1C). By looking at the common genes between the three experimental groups, we were able to generate two lists of genes that may be involved in the p53 and pRb cross-talk pathway. The first list of cross-talk candidates (designated as the p53 and pRb common gene set) 
consisted of 39 genes found to be commonly up-regulated in cells expressing either $\mathrm{p} 53$ or $\mathrm{pRb}$. The second list of possible cross-talk members (designated as the p53 and $\mathrm{pRb}$ interaction gene set) contained 140 genes that were found to be differentially expressed only when p53 and $\mathrm{pRb}$ were overexpressed together (see Supplementary Document 1). Thirty-two of the 39 common gene set cross-talk candidates were found to be up-regulated in the interaction gene set, while the remaining 7 were commonly up-regulated in cells that overexpress either p53 or pRb (Table 1). By focusing on the common and interaction gene sets, we were able to remove transcripts that were up- or down-regulated by only p53 or pRb and focus on candidates that may be involved in the p53 and $\mathrm{pRb}$ cross-talk pathway.

\section{qRT-PCR validation of microarray data in WI38 and SAOS-2 cells}

Our ultimate goal in performing the microarray analysis was to determine molecules involved in the p53 and $\mathrm{pRb}$ cross-talk pathway in order to identify and study downstream effector molecules that can be expressed to induce a p53 and/or pRb tumor suppressive function. Because of our interest in identifying downstream effector molecules, we chose five mRNA transcripts (IL-6, BTG-2, STAT4, RGS16, BCL2L11) from the set of 39 commonly up- regulated transcripts by $\mathrm{p} 53$ and $\mathrm{pRb}$ for validation via qRT-PCR. IL-6, BTG-2, STAT4, RGS16, and BCL2L11

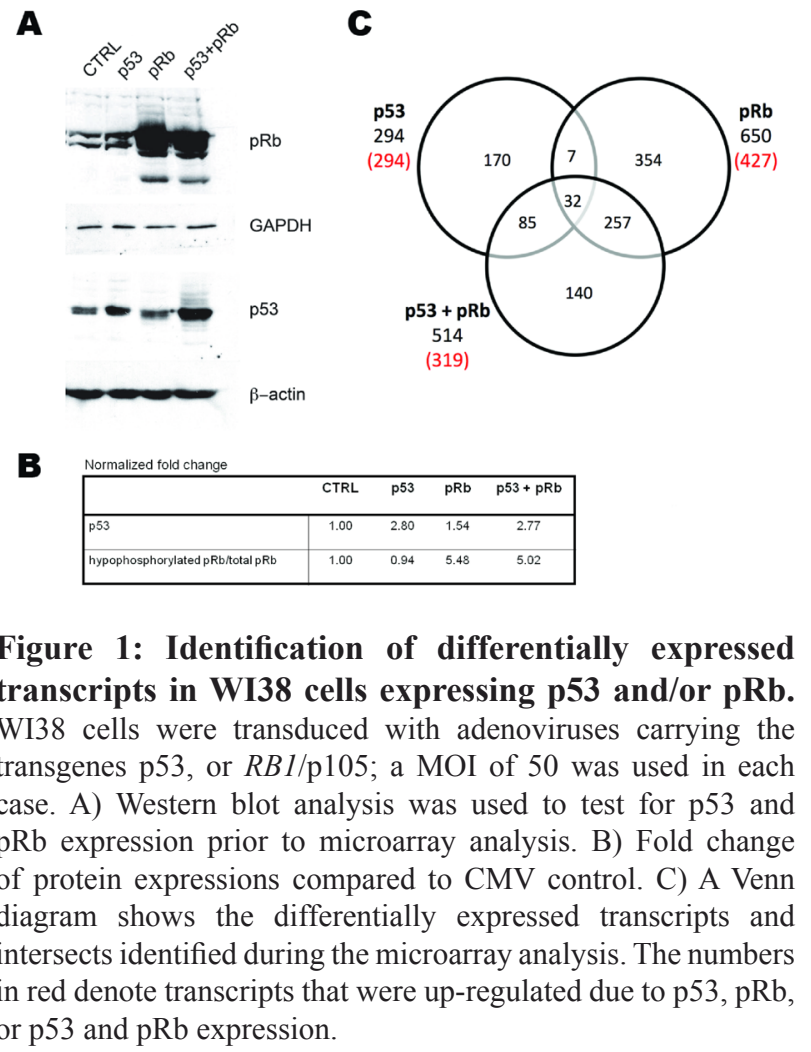

were chosen for validation because of varying function, known regulation by $\mathrm{p} 53$ and $\mathrm{pRb}$, and fold change values expression profiling assay. WI38 cells were plated and transduced with adenoviral expression vectors via the same methods used for the microarray analysis. Relative fold change was calculated for IL-6, BTG-2, STAT4, RGS16, and BCL2L11 in WI38 cells expressing p53 and/ or $\mathrm{pRb}$ as shown in Figure 2. Statistically significant upregulation of all transcripts tested except BCL2L11 was found in WI38 cells expressing p53 and pRb confirming the microarray results. Expression of p53 and pRb in WI38 cells increased mRNA expression for some of the transcripts (for example, RGS16 and BTG-2) to a greater extent than single expression of either $\mathrm{p} 53$ or $\mathrm{pRb}$. This suggests $\mathrm{p} 53$ and $\mathrm{pRb}$ are working together resulting in an additive (i.e. BTG-2) or synergistic (i.e. RGS16) effect on mRNA expression for some of the transcripts.

To further support the RNA expression profiling results, we repeated the expression of p53 and $\mathrm{pRb}$ in a p53 null, $R B 1$ mutant osteosarcoma cell line (SAOS2) and performed qRT- PCR analysis of IL-6, BTG-2,
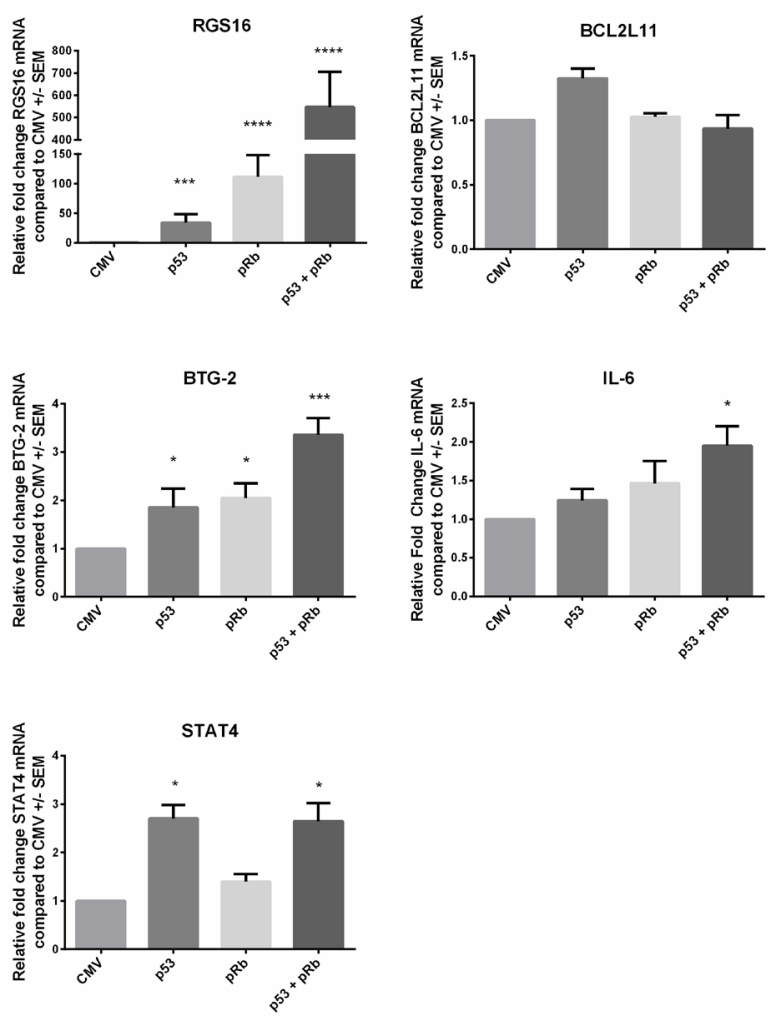

Figure 2: Validation of microarray data using qRTPCR in WI38 cells. Five transcripts RGS16, BCL2L11, BTG2, IL-6 and STAT4 from the p53 and pRb intersect were chosen for validation by qRT-PCR in WI38 cells expressing p53, $\mathrm{pRb}$, or both $\mathrm{p} 53$ and $\mathrm{pRb}$. The vector control (Ad.CMV) was used to calculate the fold change for each transcript. One-way ANOVA with Dunnett's test for multiple comparison were used to test for statistical significance $*$ p-value $<0.05, * *$ p-value $<$ $0.01, * * *$ p-value $<0.001$, and $* * * *$ p-value $<0.0001$. 
Table 2: Characterization of pancreatic cancer cell lines $[6,7,89,90]$

\begin{tabular}{|c|c|c|c|c|c|c|c|}
\hline & p53 & p16 & Ras & EGFR & Differentiation & Origin & Metastasis \\
\hline BxPC-3 & $\mathrm{mt}$ & del & wt & high & moderate & primary & no \\
\hline PANC-1 & $\mathrm{mt}$ & del & $\mathrm{mt}$ & high & poor & primary & yes \\
\hline AsPC-1 & $\mathrm{mt}$ & $\mathrm{mt}$ & $\mathrm{mt}$ & high & poor & metastatic (ascites) & yes \\
\hline MiaPaCa-2 & $\mathrm{mt}$ & del & $\mathrm{mt}$ & low & poor & primary & no \\
\hline
\end{tabular}

$\mathrm{mt}=$ mutant, del $=$ deleted, $\mathrm{wt}=$ wild-type

STAT4, RGS16, and BCL2L11. The expression of all five transcripts including IL-6 and BCL2L11 were found to be significantly increased by one-way ANOVA compared to vector control in SAOS-2 cells expressing $\mathrm{p} 53$ and/or $\mathrm{pRb}$ (Figure 3). Dunnett's test for multiple comparison found BCL2L11 expression to be significantly increased in cells expressing $\mathrm{p} 53$, pRb, and both $\mathrm{p} 53$ and $\mathrm{pRb}$ and IL-6 was found to be significantly increased in cells expressing $\mathrm{pRb}$ and $\mathrm{p} 53+\mathrm{pRb}$. Expression of IL-6 was not found to be statistically significant in SAOS-2 cells expressing p 53 due to variation between replicates (fold change $=2.86$ ).
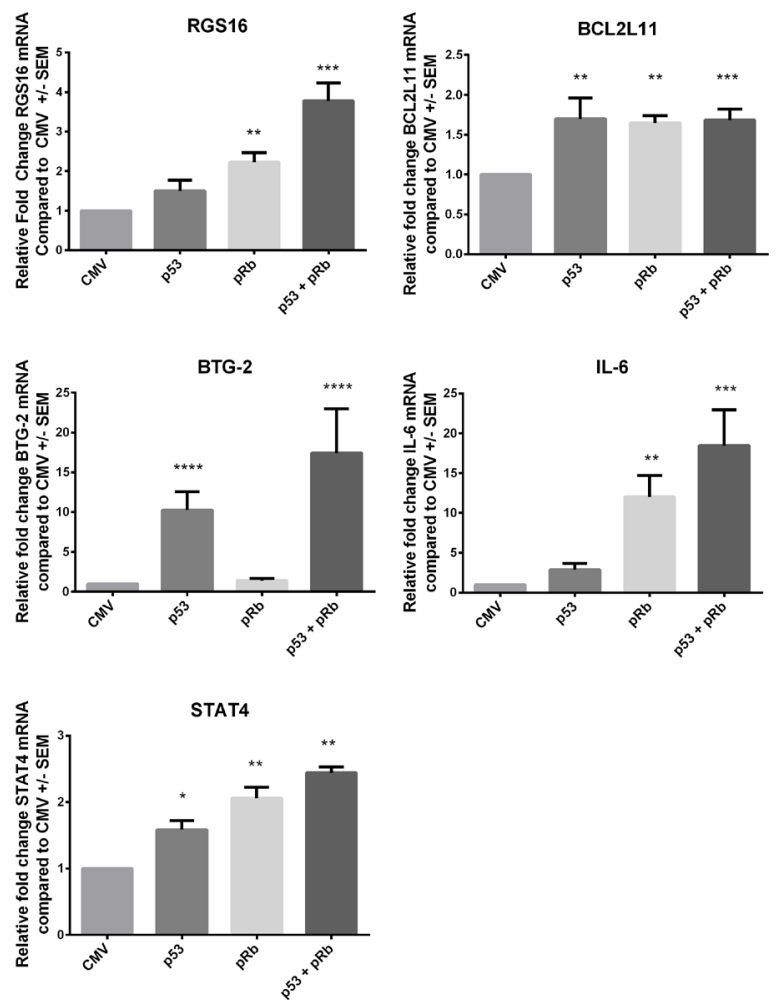

Figure 3: Validation of microarray data using qRTPCR in SAOS-2 cells. Five transcripts RGS16, BCL2L11, BTG2, IL-6 and STAT4 from the p53 and pRb intersect were chosen for validation by qRT-PCR in SAOS-2 cells expressing $\mathrm{p} 53, \mathrm{pRb}$, or both $\mathrm{p} 53$ and $\mathrm{pRb}$. The vector control (Ad.CMV) was used to calculate the fold change for each transcript. Oneway ANOVA with Dunnett's test for multiple comparison were used to test for statistical significance $*$ p-value $<0.05$, ** p-value $<0.01, * * *$ p-value $<0.001$, and $* * * *$ p-value $<0.0001$.
All five transcripts were found to be up-regulated when $\mathrm{p} 53$ and/or $\mathrm{pRb}$ were expressed in the microarray analysis and qRT-PCR analysis showed similar results in WI38 and SAOS-2 cells.

\section{mRNA expression of RGS16 is decreased in pancreatic cancer cell lines}

RGS16 was identified as a p53 and pRb crosstalk candidate in our expression profiling analysis that was validated by qRT-PCR. We chose to study the role of RGS16 in pancreatic cancer cell migration due in part to its down-regulation in patients with metastasized pancreatic cancer and the high rate of p53 mutations (50-70\%) and p16 deletions (85\%) affecting both the p53 and pRb pathways in this disease $[6,7,26]$. We first investigated the relative expression of RGS16 mRNA in four pancreatic cancer cell lines (BxPC-3, MIA PaCa2, PANC-1, and AsPC-1) in order to characterize the endogenous expression of RGS16. Expression of RGS16

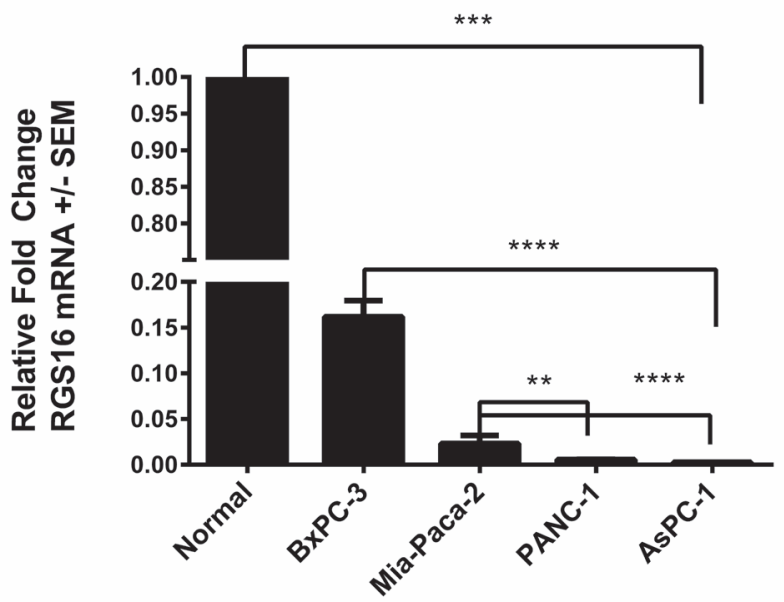

Figure 4: Decreased expression of RGS16 mRNA relative to total RNA extracted from normal human pancreatic tissue. Expression of RGS16 was measured using qRT-PCR in BxPC-3, MIA PaCa-2, PANC-1, and AsPC-1 cells. Relative fold change was measured using total RNA extracted from normal human pancreatic tissue as the control. One-way ANOVA with Tukey's test for multiple comparison were used to test for statistical significance between the cell lines and control $*$ p-value $<0.05, * *$ p-value $<0.01, * * *$ p-value $<0.001$, and $* * * *$ p-value $<0.0001$. 
was measured by qRT-PCR analysis and the relative RGS16 mRNA fold change was calculated in the four cell lines compared to total RNA from normal human pancreatic tissue. Expression of RGS16 was decreased in all four lines compared to control with BxPC-3 having the highest expression of RGS16 mRNA (Figure 4). Expression of RGS16 varied between the four lines with BxPC-3 and MIA PaCa-2 having significantly higher expression of RGS16 than PANC-1 and the metastatic derived AsPC-1 cells. RGS16 expression corresponded with the more differentiated and less aggressive cell lines having higher levels of RGS16 than the more aggressive and/or metastatic cell lines (Table 2).

\section{RGS16 inhibited migration of BxPC-3 and AsPC- 1 pancreatic cancer cells but not PANC-1}

To test the hypothesis that RGS16 inhibits pancreatic cancer cell migration, we exogenously expressed RGS16 in BxPC-3, PANC-1, and AsPC-1 cells with an adenoviral vector and used wound healing assays to measure cell migration. We chose BxPC-3, PANC-1, and AsPC-1 because these three cell lines are
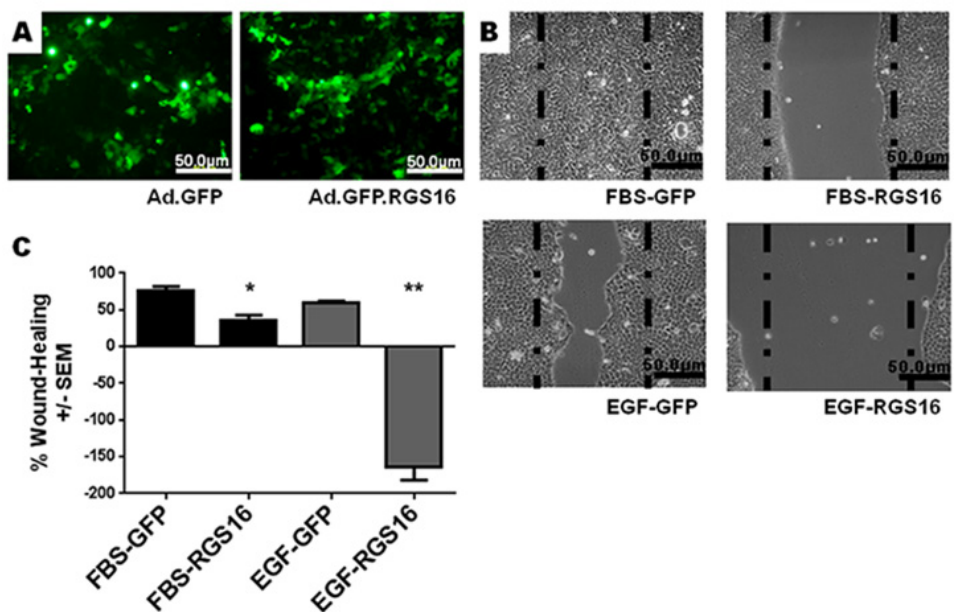

Figure 5: Expression of RGS16 inhibited migration of BxPC-3 cells. BxPC-3 cells were transduced with 50 MOI of Ad.GFP (CTRL) or Ad.GFP.RGS16. A) Virus transduction was verified by fluorescent microscopy. B) Images (100x) and measurements of wounds were taken prior and 16 hours after addition of media supplemented with FBS (10\%) or EGF (100ng/ml). The dashed lines represent size of scratch at time 0 . C) Mean Percentage of wound healing \pm SEM of three separate experiments (three scratches / well) was determined. Student's t-test was used to determine statistical significance compared to control $*$ p-value $<0.05, * *$ p-value $<0.01$.

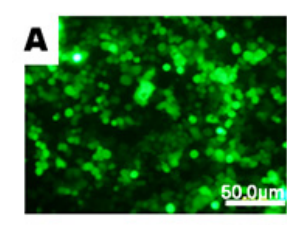

Ad.GFP

C

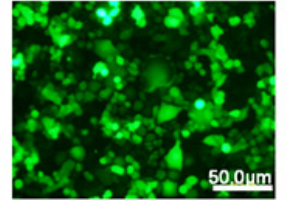

Ad.GFP.RGS16

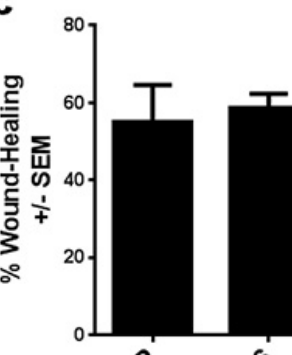

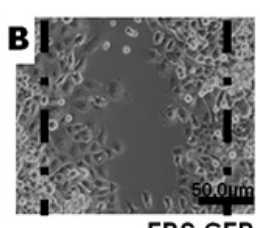

FBS-GFP

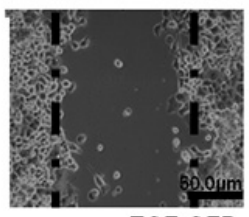

EGF-GFP

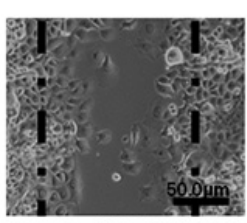

FBS-RGS16

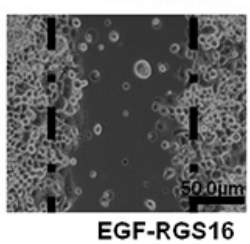<smiles>Cc1ccc(OC(=O)OCCOc2ccccc2)cc1</smiles>

Figure 6: Expression of RGS16 did not inhibit migration of PANC-1 cells. Wound healing assays were performed as described in Figure 2. A) Fluorescent microscopy was used to verify virus transductions: B) $100 \mathrm{X}$ images were taken of migrating cells and C) percentages of wound healing were calculated at $24 \mathrm{hrs}$ following addition of FBS or EGF. 
derived from tumors with varying expression of RGS16, differentiation status, mutations, presence of metastases, and expression of Epidermal Growth Factor Receptor (EGRF, Table 2). We expressed RGS16 using adenoviral vector that contains RGS16 plus a GFP reporter (Ad.GFP. RGS16) and used a vector expressing only GFP (Ad.GFP) as the control. Expression of RGS16 protein correlated with GFP expression in cells treated with Ad.GFP.RGS16 (Supplementary Figure 1). Fluorescent microscopy was used to determine viral transduction prior to experiment (Figures 5a, 6a, and 7a). EGF was used to stimulate cell migration because EGFR is overexpressed in pancreatic cancer and is linked with development, invasion, and decreased survival in pancreatic cancer [32-34]. RGS16 significantly inhibited FBS- and EGF-induced migration of BxPC-3 cells and FBS-induced migration of AsPC-1 cells, but had no effect on FBS and EGF induced migration of PANC-1 cells (Figures 5-7).

Interestingly, expression of RGS16 in BxPC-3 cells incubated in media supplemented with EGF caused an increase in wound width compared to control 16 hours after the start of the experiment. However, MTT assay revealed that there was no statistically significant change in cell viability of FBS or EGF treated BxPC-3, PANC-1 or AsPC-1 following expression of RGS16 compared to control cells expressing GFP (Supplementary Figure 2).

\section{Expression of RGS16 inhibited EGF induced invasion of BxPC-3 and AsPC- 1 cells}

RGS16 inhibited EGF induced migration of BxPC3 and AsPC-1 cells, we further investigated if RGS16 can inhibit EGF induced invasion of these pancreatic cancer cells using matrigel invasion chambers. Media supplemented with EGF was used as the chemoattractant to induce migration and invasion of BxPC-3 and AsPC-1 cells expressing GFP and or RGS16. Expression of RGS16 significantly inhibited EGF induced invasion of the BxPC3 and AsPC-1 cells by $35.73 \%$ and $66 \%$ respectively, compared to control (Ad.GFP) (Figure 8).

\section{DISCUSSION}

\section{Significance of investigating p53 and pRb cross- talk}

Historically, investigations of p53 and pRb regulated transcription have focused on identifying the individual downstream targets of p53 and pRb. However, cell fate is not determined solely by one signaling pathway but by many pathways that communicate through a network
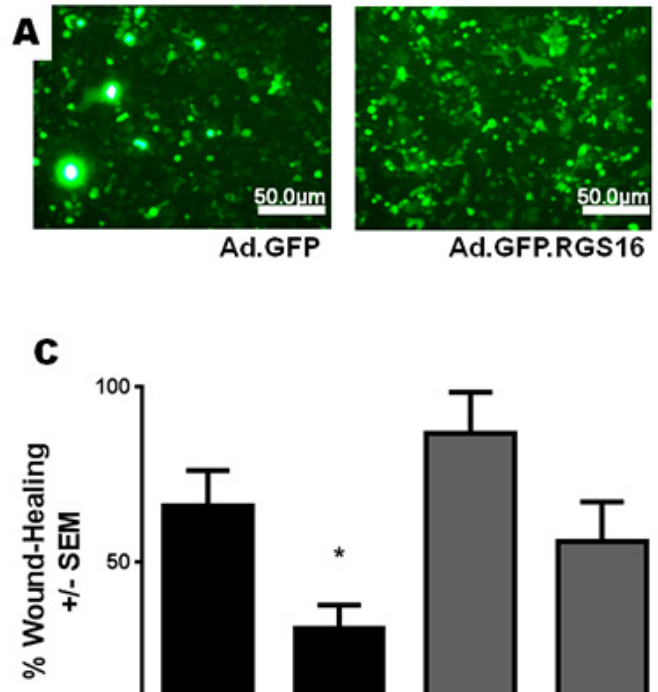

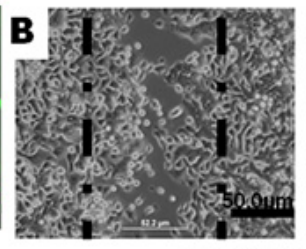

FBS-GFP
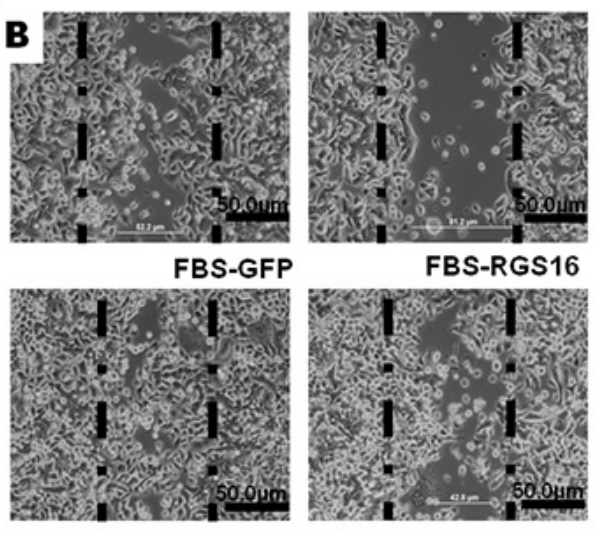

EGF-GFP

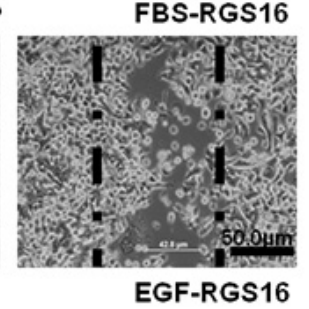

Figure 7: Expression of RGS16 inhibited migration of AsPC-1 cells. Wound healing assays were performed as described in Figure 2. A) Fluorescent microscopy was used to verify virus transductions: B) $100 \mathrm{X}$ images were taken of migrating cells and C) percentages of wound healing were calculated at $24 \mathrm{hrs}$ following addition of FBS or EGF. 
of signaling molecules. Cross-communication between pathways allows the integration of the exogenous and endogenous signals in a cell to aid in the determination of cell fate. Previous studies have found that co-expression of $\mathrm{p} 53$ and $\mathrm{pRb}$ in cancer cells with compromised p53 and $\mathrm{pRb}$ activity inhibited $\mathrm{p} 53$ mediated apoptosis and promoted cell cycle arrest suggesting p53 and pRb crosstalk to regulate cellular fate $[35,36]$. Furthermore, data from previous studies suggests $\mathrm{p} 53$ and $\mathrm{pRb}$ may also cooperate to inhibit cancer progression. Patients diagnosed with breast cancer and treated with adjuvant chemotherapy had a better prognosis to adjuvant chemotherapy if they had functional $\mathrm{p} 53$ and $\mathrm{pRb}$ [37].

To our knowledge this is the first study that examines altered gene expression when $\mathrm{p} 53$ and $\mathrm{pRb}$ are expressed together or separately with the purpose of finding genes co-regulated by both tumor suppressor genes. How $\mathrm{p} 53$ and $\mathrm{pRb}$ cross-communicate to regulate cellular functions or cooperate to inhibit cancer progression still remains largely unknown. The p53 and $\mathrm{pRb}$ pathways are commonly altered during tumorigenesis. Due to the dynamic properties of cell signaling, the study of genes dually regulated by $\mathrm{p} 53$ and $\mathrm{pRb}$ will provide a valuable insight into the collaborative cancer preventative properties of these two tumor suppressor proteins.

Transcriptional regulation may be one method used by $\mathrm{p} 53$ and $\mathrm{pRb}$ to coordinate cellular functions. For example, the cyclin kinase inhibitor p21 is a down- stream target gene of p53 that inhibits phosphorylation and inactivation of $\mathrm{pRb}$ [25]. Transactivation of $\mathrm{p} 21$ demonstrates a mechanism by which p53 can coordinate with $\mathrm{pRb}$ to initiate cell cycle arrest. However, this only begins our understanding of the complex regulation of cellular programs.

\section{Change in RNA expression profiles of WI38 cells expressing both $\mathrm{p53}$ and $\mathrm{pRb}$ compared to expression of $\mathrm{p} 53$ and $\mathrm{pRb}$ alone, identification of cross-talk candidates, and validation by $q R T-P C R$}

In this study, we identified genes that may be regulated by $\mathrm{p} 53$ and $\mathrm{pRb}$ and compiled two lists of $\mathrm{p} 53$ and $\mathrm{pRb}$ cross-talk candidates by expressing $\mathrm{p} 53$ and/ or $\mathrm{pRb}$ in WI38 cells. Although p53 has transcriptional repression activity, our microarray analysis did not detect any down-regulated transcripts in the WI38 cells expressing p53 $[38,39]$. The deficit of p53 downregulated transcripts in our microarray analysis compared to previous studies could be due to our method of p53 activation, cell type, or $\mathrm{p} 53$ levels, which have previously been found to induce a distinct $\mathrm{p} 53$ response with a small set of overlapping genes [40, 41]. Our expression profiling analyses were conducted in normal lung fibroblasts cells instead of cancer epithelial cells. Absence of p53 downregulated genes in the p53 expressing WI38 cells could
A

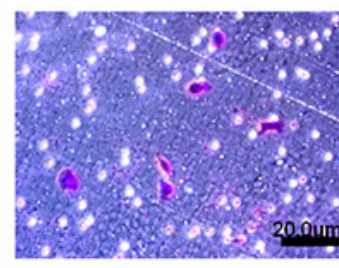

EGF-GFP

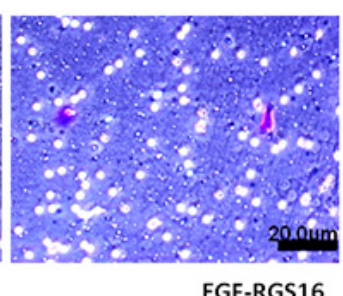

EGF-RGS16

C

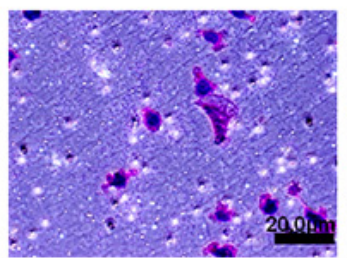

EGF-GFP

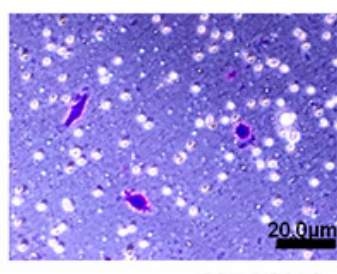

EGF-RGS16
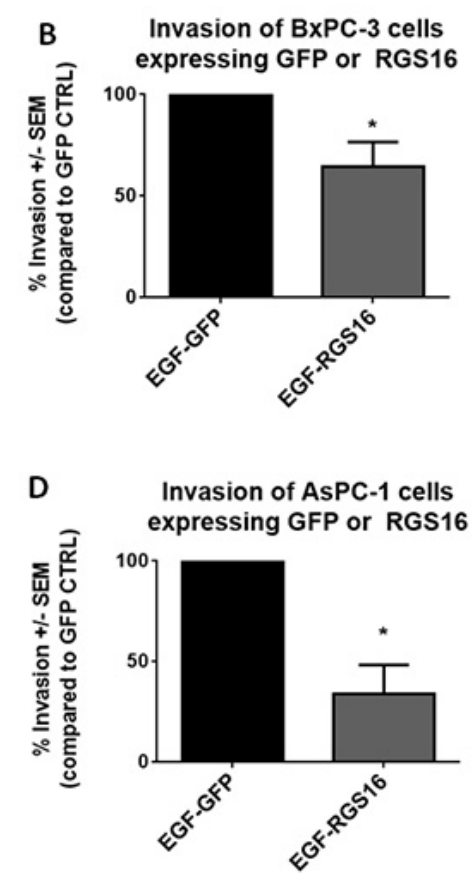

Figure 8: Expression of RGS16 inhibited invasion of BxPC-3 and AsPC-1 cells. Matrigel invasion chambers were used to measure cell migration and invasion of GFP and/or RGS16 expressing BxPC-3 (A \& B) and AsPC-1 (C \& D) cells using EGF as a chemoattractant. Migrated cells were stained with Crystal Violet and counted at 200x magnification (A \&C). Percent invasion was calculated for each cell line (B \& D) * p-value $<0.05$. 
also be attributed to the ability of p53 and pRb to alter each other's transcriptional activation or repression functions in normal cells that contain intact pathways. Previous studies that discovered p53 down-regulated targets using expression profiling were done in cancer cells with mutated or null p53 and wild-type $R B 1$ such as PC-3, HCT116, and H1299 cells [38, 42].

There were 319 upregulated transcripts when p53 and $\mathrm{pRb}$ were expressed together compared to 427 and 295 in the WI38 cells expressing pRb and p53 respectively. The change in upregulated genes suggests p53 and pRb can alter one another's ability to regulate gene expression. Management of p53 and $\mathrm{pRb}$ processes may require p53 and $\mathrm{pRb}$ to regulate gene expression in an opposing manner. Expression of an embryonic development gene, Placenta- specific 1 (PLAC1), has recently been found to be down-regulated by $\mathrm{p} 53$ and up-regulated by $\mathrm{pRb}$ demonstrating how $\mathrm{p} 53$ and $\mathrm{pRb}$ can play contrasting roles to regulate cellular processes [43].

$\mathrm{pRb}$ is most associated with transcriptional repression of E2F target genes preventing transcription of genes needed for the continuation of the cell cycle [44-46]. However, binding of E2F by $\mathrm{pRb}$ is not needed to promote transcription, suppress tumor growth and induce cellular differentiation or senescence $[47,48]$. In fact, $\mathrm{pRb}$ has been found to act as a co-activator for several transcription factors including Sp-1, RUNX-2, MyoD, and several nuclear receptors (including NR4A1) resulting in cellular differentiation $[48,49]$. We found more transcripts that were up-regulated in WI38 cells expressing $\mathrm{pRb}$ than downregulated demonstrating its function as a transcription co-activator. There is still a lot not known about $\mathrm{pRb}$ regulation, therefore, this study could contribute to the identification of genes up-regulated by $\mathrm{pRb}$ and understanding of the function of $\mathrm{pRb}$ as a transcriptional co-activator.

Candidates for the $\mathrm{p} 53$ and $\mathrm{pRb}$ cross-talk pathway were chosen based on whether (1) the transcripts were differentially expressed in both WI38-p53 and WI38pRb-expressing cells (the common gene set), or (2) only in WI38 cells that simultaneously expressed p53 and pRb (interaction gene set). By focusing on the p53 and pRb common and unique genes, we were able to remove from our analysis genes regulated by p53 or pRb alone. Several of the p53 and pRb common gene set (RGS16, BTG-2, GDF15, VCAN, D4s234e/NSG1, AKR1B10 and AREG) and interaction gene set (F11R, TNFRSF10C, CERS6, HDM2, SESN1, RBM38 and PMAIP1/NOXA) cross-talk candidates have been previously found to be up-regulated by $\mathrm{p} 53$, and this data is in agreement with our microarray results $[15,41,50-58]$. Only a few of the downregulated p53 and pRb cross-talk candidates have previously been found by other studies to be downregulated by p53 (MCM3, BUB1, and CDT1) or pRb individually (VRK1, MCM3, and CDT1) [38, 59-62]. Although several of our p53 and pRb cross-talk candidates have previously been found regulated by $\mathrm{p} 53$, regulation of these transcripts by $\mathrm{pRb}$ is not known.

Our expression profiling analysis was performed using a normal cell line in order to avoid any mutations that could be present up- or downstream of p53 and pRb that could hinder identification of downstream targets of both genes. Although we expressed p53 and pRb using adenoviruses in normal cells, the fold change of p53 and hypophosphorylated pRb proteins compared to CMV control were equivalent to or less than fold change values in WI38 cells incubated in serum free media to induce quiescence (fold change p53 after 24 hours in serum free media $=5.5$ ) or MCF7 cells undergoing confluence induced cell growth arrest (fold change hypophosphorylated $\mathrm{pRb} /$ total $\mathrm{pRb}=6.00)$ [30, 31]. This data suggests the concentration of virus used did not exceed endogenous protein expression of p53 and the active hypophosphorylated form of $\mathrm{pRb}$. However, the use of a normal cell line with wild-type p53 and RB1 could make it difficult to identify cross-talk molecules due to possible interactions between endogenous and exogenous p53 and pRb. To investigate if exogenous and endogenous $\mathrm{p} 53$ and $\mathrm{pRb}$ interactions could influence expression profiles expression of RGS16, BCL2L11, BTG-2, IL-6, and STAT4, were measured using qRT-PCR in the p53 null and $\mathrm{pRb}$ mutated osteosarcoma cell line SAOS-2. Expression of all transcripts in the $\mathrm{p} 53$ and $\mathrm{pRb}$ expressing SAOS-2 cells were found increased with differences in magnitude of expression as they did in our WI38 microarray data and qRT-PCR results. Interestingly, in the microarray data, STAT4 was found to be differentially expressed in WI38 cells expressing p53 and pRb but not in cells expressing both genes. However qRT-PCR analysis found a statistically significant increase in STAT4 expression in WI38 and SAOS-2 cells expressing p53 and $\mathrm{pRb}$. The statistical analyses of expression profiling data or the sensitivity of microarray signal detection could account for the failure to observe differential expression of STAT4 in WI38 cells expressing p53 and pRb.

\section{RGS16 significance and signaling in cancer}

RGS16 was of interest to our study for two reasons: 1) RGS16 regulates GPCRs, which are common targets for deregulation in cancer and 2) RGS16 has been linked to regulating the MAPK/RAS, PI3K/AKT, RhoA, and SDF-1/CxCR4 oncogene pathways [15, 17-19, 63]. Investigations have found that oncogene pathways can feed into one another and bypass or overcome the inhibitory effects of monoclonal antibodies or other targeted inhibitors. For example, in melanoma, increased production of VEGF or increased expression or activation of the platelet-derived growth factor receptor $\beta$ or insulin like growth factor 1 receptor is associated with resistance to BRAF inhibitors demonstrating mechanisms cancer cells use to overcome single target modalities [64]. 
Therefore investigation of RGS16, a protein known to modulate several oncogene pathways will aid in understanding mechanisms by which cells alter multiple signaling pathways to prevent carcinogenesis that could be used for future drug development.

We chose to study the function of RGS16 in pancreatic cancer because only $5.7 \%$ (1 out of 17 ) of pancreatic tumors with lymph-node metastases had expression of RGS16 compared to 70.6\% (12 out of 17) of pancreatic tumors with non-metastasized pancreatic cancer [26]. Furthermore, decreased expression of RGS16 was associated with poor pancreatic cancer patient survival indicating the potential of RGS16 as a pancreatic cancer prognostic marker [26].

Few reports have been published that describe the impact of RGS16 on cancer cell signaling and progression. Although increased expression of RGS16 has been found in pediatric high hyperdiploid acute lymphoblastic leukemia (ALL) and colon cancer, functional analysis of RGS16 has not been performed to identify any oncogenic function in these cancers [26, 65, 66]. Functional and expression analysis of RGS16 has been performed in breast cancers. The RGS16 promoter is located at a site that is vulnerable to allelic imbalances in a subset of breast cancers that can result in promoter methylation of RGS16 in $10 \%$ of these cancers [25]. Liang et al. (2009) found that RGS16 overexpression in breast cancer cell lines decreased EGF induced proliferation and AKT activation by binding to the p85-alpha subunit of PI3K preventing the phosphorylation of AKT [19]. RGS16 has also been associated in the anti- proliferative effect of retinoic acid in neuroblastoma cells and the cytotoxic effect of histone deacetylase inhibitor Vorinostat in triple negative breast cancers $[67,68]$. The current data suggests RGS16 plays a role in cancer signaling, however, more research is needed to delineate the function of RGS16 in cancer cells.

\section{RGS16 and cell migration}

RGS16 has been linked with inhibition of cell migration in a canonical (through regulation of GPCR signaling) and non-canonical pathways in normal cells. RGS16 inhibits megakaryocytes and $\mathrm{T}$ lymphocyte migration by regulating the activation of the GPCR CxCR4 and decreases $\mathrm{T}$ helper type 2 and 17 cell trafficking through regulation of CCR4 and CCR10 chemokine pathways representing the canonical form of RGS signaling $[17,69,70]$. The activation of RhoA, a small GTPase involved in reorganizing actin cytoskeleton and a mediator of EGF induced invasion of pancreatic cancer cell lines is inhibited in MCF-7 cells by the relocation of Ga13 to the plasma membrane by RGS16 preventing G $\alpha 13$ mediated activation of RhoA [18, 71]. The regulation of RhoA activation by RGS16 is an example of a non-canonical mechanism used to regulate signaling. These studies show mechanisms by which
RGS16 can regulate cell migration. To date, this is the first report demonstrating RGS16 induced inhibition of cancer cell invasion.

The findings from our study suggest RGS16 is regulated by $\mathrm{p} 53$ and $\mathrm{pRb}$ and functions to inhibit pancreatic cancer cell migration and invasion; however this effect was cell line dependent. PANC-1 cell migration induced by FBS or EGF was not inhibited by RGS16, this could be due to different mutations in PANC-1 compared to the other cell lines that prevent RGS16 inhibition of FBS or EGF induced cell migration. Although not commonly associated with p53 and pRb signaling, regulation of cellular migration and invasion by both tumor suppressors has become evident over the course of the past several years. p53 has been found to regulate cell polarization and migration of cells predominately by inhibiting Rho signaling [72]. p53 also inhibits cancer cell invasion by inhibiting activity or expression of matrix metalloproteinases (MMPs) [73-76]. pRb's role in cell migration has recently come to light. pRb has been implicated as an important factor in regulating neuronal cell migration and was recently found to inhibit CD44 induced collective cell migration of breast cancer cells [77, 78]. $\mathrm{pRb}$ is linked to regulating invasion through its ability to bind and inhibit E2F induced transcriptional activation of the MMPs 9, 14, and 15 [79]. Knock-down of E2F1 and E2F3 inhibited migration and invasion of non-small cell lung cancer cells [79]. RGS16 may be another mechanism employed to regulate cell migration and invasion by $\mathrm{p} 53$ and $\mathrm{pRb}$.

\section{Future studies and conclusions}

This is the first report of regulation of RGS16 by $\mathrm{pRb}$ and RGS16-mediated inhibition of EGF- induced migration and invasion in normal and cancer cells. This study focused on examining migration and invasion mediated by the EGF/EGFR pathway. However, a single RGS protein can interact and regulate signaling of multiple pathways $([16,80])$. Future studies are needed to determine if RGS16 can inhibit cell migration and invasion through other pathways such as the SDF-1/ $\mathrm{CxCR} 4$ pathway which is deregulated in pancreatic cancer ([21]).

By utilizing microarray expression profiling, we have 1) identified p53 and pRb regulated candidates genes involved in coordinating cancer suppression processes and determining cell fate, 2) and identified a possible role for the cross-talk candidate RGS16 in inhibiting pancreatic cancer cell migration and invasion. Our study suggests that the loss of RGS16 promotes pancreatic cancer metastasis by removing the inhibitory function of RGS16 on cell migration and invasion. Our study further supports the use of RGS16 as a prognostic marker for predicting pancreatic cancer metastasis previously described by Kim et al. that can be used to assess eligibility of patient for surgery 
[26]. By investigating the $\mathrm{p} 53$ and $\mathrm{pRb}$ cross-talk and the role of RGS16 in pancreatic cancer cell migration, we have uncovered a novel regulator of metastatic processes that could be a future target in developing treatments to prevent the spread of pancreatic cancer.

\section{MATERIALS AND METHODS}

\section{Cell culture and virus transductions}

The human lung fibroblast WI38 cell line, osteosarcoma cell line SAOS-2 (p53 null and truncated RB1), and the pancreatic cancer cell lines, BxPC-3, AsPC-1, MIA PaCa-2, and PANC-1 were purchased from the American Type Culture Collection (Manassas, VA, USA). WI38 cells were grown in Hyclone MEM/ EBSS (ThermoFisher Scientific, Waltham, MA) media supplemented with $10 \%$ research grade fetal bovine serum (FBS) (PAA Laboratories, Dartmouth, MA) and $1 \%$ Penicillin Streptomycin (Corning, Corning, NY) and SAOS-2, MIA PaCa-2, and PANC-1 cells were grown in Hyclone High Glucose DMEM (ThermoFisher Scientific, Waltham, MA) supplemented with 10\% FBS and 1\% Penicillin Streptomycin. BxPC-3 and AsPC-1 were cultured in RPMI supplemented with $10 \%$ or $15 \%$ FBS (respectively) and 1\% Penicillin Streptomycin. Cells were cultured at $37^{\circ} \mathrm{C}$ in a humidified $5 \% \mathrm{CO}_{2}$ incubator.

Ad.CMV (adenovirus with CMV promoter) and Ad.CMV.p53 (Adenovirus containing wild- type p53 gene under control of CMV promoter) viral vectors were generated using the AdEasy system (Carlsbad, CA). The Ad.CMV.pRb (Adenovirus containing RBI gene cDNA under control of CMV promoter) vector was provided by Dr. Juan Fueyo (M.D. Anderson Cancer Center, The University of Texas). The Ad.GFP and Ad.GFP.RGS16 viruses were purchased from Vector Biolabs (Philadelphia, PA). Viruses were amplified and titered as previously described [81-83].

\section{Microarray expression profiling}

For expression profiling, WI38 cells were transduced with each of the following vectors or vector combination: (1) adenovirus vector with no insert (Adenoviral CMVvector ctrl), (2) Ad.CMV.p53, (3) Ad.CMV.pRb, and (4) both Ad.CMV.p53 and Ad.CMV.pRb. Vectors were added at a multiplicity of infection (MOI) of 50 to $80 \%$ confluent WI38 cells in MEM/EBSS supplemented with $2 \%$ heatinactivated FBS. Culture media were replaced with $10 \%$ FBS and $1 \%$ Penicillin/Streptomycin supplemented MEM/EBSS medium 16 hours after vector addition; cells were collected after 48 hours. Four biological replicates were performed for each of the four expression studies. Immunoblots were used to verify increased expression of p53 and/or pRb in the WI38 samples prior to microarray analysis.

Total RNA was isolated from transduced WI38 cells using TRIzol reagent (Invitrogen, Carlsbad, CA) according the manufacturer's protocol. Using a universal reference design, two RNAs (transduced WI38 cells + Agilent (Santa Clara, CA) human universal reference RNA) were hybridized to Agilent $44 \mathrm{~K}$ whole human genome expression arrays. Total RNAs were labeled with either cyanine (Cy)-3-CTP and Cy5-CTP (Perkin Elmer, Waltham, MA) using Agilent QuickAmp cRNA labeling kits. Following purification, Cy3- and Cy5-labeled cRNAs were combined and hybridized for 17 hours at $65^{\circ} \mathrm{C}$ in an Agilent hybridization oven. Microarrays were then washed and scanned using Agilent DNA Microarray Scanner.

\section{Statistical Analysis of Expression Profiling Data}

Lowess-normalized feature intensities were extracted from the scanned image using Feature Extraction (Agilent). These data were exported as tab-delimited files (one file per sample) to Microsoft Excel for filtering. For each feature, data were removed if both channels reported values not well-above background according to default Feature Extraction Criteria. For each comparison, log base-2 ratios of each sample to universal reference RNA were collated into a single table. Features for which fewer than $50 \%$ of all samples had a present value were removed from further analysis.

The resulting tables were imported into Multiple Experiment Viewer (MEV) v4.3. Log base 2 ratios were compared between each of three sample sets (p53 expressed samples. $R B 1$ expressed samples and $\mathrm{p} 53$ and $R B 1$ coexpressed samples) and the adenovirus vector control samples by Significance Analysis of Microarrays [84]. We used a conservative threshold whereby only genes for which MEV reported a false discovery rate of $0 \%$ were considered significantly differentially expressed.

Data extracted using Feature Extraction was uploaded to the NCBI's Gene Expression Omnibus (GEO) public database and is available via access number GSE59660.

\section{Real-time PCR analysis}

Total RNA was isolated from cells using TRIzol reagent (Invitrogen, Carlsbad, CA) according to the manufacturer's protocol. Total RNA was reverse transcribed into cDNA using the High Capacity cDNA Reverse Transcription kit from Applied Biosystems (Foster City, CA) according to the manufacturer's protocol. Real-Time PCR was performed using the Applied Biosystems TaqMan Gene Expression Assays in the ABI 7000 detection system. TaqMan probes were purchased from Applied Biosystems (Foster City, 
CA) IL-6 (HS00197982_m1), BCL2L11 (BCL2L11) (HS00197982_m1), RGS16 (HS00892674_m1), BTG2 (HS00198887), STAT4 (HS00231372_ml) and GAPDH (HS02758991). Human pancreatic total RNA used for comparing the expression of RGS16 mRNA was purchased from Agilent Technologies (Cedar Creek, TX). The relative fold change for each marker was calculated using the $2^{-\triangle \Delta C T}$ analysis according to Livak et.al and statistical significance was determined using a one way ANOVA with a Dunnett's or Tukey (pancreatic cancer cell lines) post-hoc test, using Prism V6.0c (GraphPad Software, Inc., La Jolla, CA) [85].

\section{Western blot analysis}

WI38 or Saos- 2 cells were lysed in whole cell lysis buffer containing 50mM TRIS (pH7.4), 5mM EDTA 250mM NACL, 50mM NaF, $0.1 \mathrm{mM} \mathrm{Na}_{3} \mathrm{VO}_{4}, 0.1 \%$ Triton $\mathrm{X}-100$ and protease inhibitors (Pierce Protease inhibitor Tablets 88661; Thermo Scientific, Rockford, IL). Protein extracts (50ug) were loaded onto $8 \%$ polyacrylamide gels and proteins were separated using sodium dodecyl sulfate-polyacrylamide gel electrophoresis (SDS-PAGE). Blots were blocked 1 hour in 5\% dry non-fat milk diluted in Tris-buffered saline solution containing $0.1 \%$ Tween-20 (TBS-T). Membranes were probed overnight at $4^{\circ} \mathrm{C}$ with mouse anti-p53 (SC-DO1, 1: 1000) or mouse anti-pRb (SC-IF8, 1:500) antibodies from Santa Cruz Biotechnology (Dallas, TX). Following primary antibody incubation the membranes were washed and probed with Horseradish peroxidase (HRP)-conjugated goat anti-mouse (1:5000) secondary antibodies (Rockland, Gilbertsville, PA) for 1 hour at room-temperature. Primary and Secondary antibodies were diluted in TBS-T. Blots were washed 5 minutes in TBS-T three times and Amersham ECL prime western blotting detection reagent was added in order visualize the protein bands (RPN2232, GE Life Sciences, Pittsburgh, PA). Western blot images were captured using FOTODYNE FOTO/Analyst FX (Hartland, WI) imaging camera. Membranes were normalized using mouse anti-actin (1:1000). Densitometry was performed using TotalLab Quant software (TotalLab Ltd, UK).

\section{Wound healing Assay}

Pancreatic cancer cells (BxPC-3, AsPC-1 and PANC-1) were placed in a 6 well plate at approximately $70 \%$ confluency. The following day, 50 Multiplicity of Infection (MOIs) of Ad.GFP (control) or Ad.GFP.RGS16 were added to the cells in media containing $2 \%$ heatinactivated FBS for 24 hours. The media was changed to complete media (10\% FBS for BxPC-3 and PANC- 1 or $15 \%$ for AsPC-1) for $24 \mathrm{hrs} .48$ hours after the addition of the virus the media was changed from complete media to media supplemented with $0.5 \% \mathrm{FBS}$ and $1 \% \mathrm{P} / \mathrm{S}$ for 24 hours. Three wounds or scratches were made per well using a p200 pipette tip in PBS. The cells were washed three times with PBS and incubated for 16-24 hours in complete media or media supplemented with $100 \mathrm{ng} / \mathrm{ml}$ of EGF. FBS or EGF was added to induce cell migration at a concentration previously described in [86-88]. Wound widths were measured and images taken at 0,16 , or $24 \mathrm{hrs}$ after addition of media supplemented with FBS or EGF at 100x magnification using an Olympus DP71 microscope (Center Valley, PA). Efficacy of virus transduction was confirmed using fluorescent microscopy to examine GFP expression prior to the start of the experiment. Percent wound healing was determined using the following equation; $\%$ wound healing $=([$ initial scratch width - final scratch width]/ initial scratch width)*100. Three replicates were performed for each cell line.

\section{Invasion Assay}

BD Bio Coat Matrigel Invasion chambers (Bedford, MA) containing membrane with 8 um pores were used to assess the role of RGS16 to inhibit pancreatic cancer cell migration and invasion. $\mathrm{BxPC}-3$ cells were plated into 6-well dish, 24 hours later 50 MOIs of Ad.GFP or Ad.GFP. RGS16 virus were added to the cells followed by 24 hour incubation in complete media and 24 hours in lowserum media as described in the wound healing section. Chambers were re-hydrated in RPMI containing 1\% $\mathrm{P} / \mathrm{S}$ and $0.1 \% \mathrm{BSA}$ for 2 hours at $37^{\circ} \mathrm{C}$. BxPC-3 and AsPC-1 cells were collected and $25 \times 10^{4}$ cells were added to the top of the chambers in RPMI supplemented with $1 \% \mathrm{P} / \mathrm{S}$ and $0.1 \%$ BSA. RPMI supplemented with $100 \mathrm{ng} / \mathrm{ml}$ EGF, $1 \% \mathrm{P} / \mathrm{S}, 0.1 \% \mathrm{BSA}$ was added to lower portion and the chambers were incubated for 18 (AsPC-1) or 20 (BxPC-3) hours at $37 \mathrm{C}$. The non-migrating cells were removed using a cotton swab and the invaded cells were fixed using 100\% methanol $(\mathrm{MeOH})$ for 5 minutes and stained using $0.5 \%$ crystal violet plus $20 \% \mathrm{MeOH}$ (10-15 mins). Invaded cells were counted using 200x magnification with 12 different views. Percentage of invasion compared to GFP control was calculated for each cell line [(\# of invaded cells ${ }_{\text {treated }}$ / \# of invaded cell $\left.\left.{ }_{\text {control }}\right) * 100\right]$. Three replicates were performed for each cell line.

\section{Statistical Analysis}

Statistical significance for the wound healing and invasion assays was calculated using Student's $t$-test using Prism V6.0c (GraphPad Software, Inc., La Jolla, CA). Statistical Analysis tests used for expression profiling and qRT-PCR analyses are listed in their respective sections. 


\section{Abbreviations}

qRT-PCR: quantitative real-time PCR; $\mathrm{pRb}$ : retinoblastoma protein; $R B 1$ : retinoblastoma gene; CMV: Cytomegalovirus; MOI: multiplicity of infection; RGS16: regulator of $G$ protein signaling 16; EGF: epidermal growth factor; EGFR; epidermal growth factor receptor; GPCR: G protein coupled receptor.

\section{ACKNOWLEDGMENTS}

We gratefully acknowledge the Marshall University Biochemistry and Microbiology Department for its support. The present studies were supported by the NASA WV Space Grant Consortium, award \#NNX10AK62H. Microarray and related data analyses were performed by the Marshall University School of Medicine Genomics Core Facility, which was supported by NIH grants P20RR016477 and P20GM103434 to the WV- INBRE program. The funders had no role in study design, data collection and analysis, decision to publish, or preparation of the manuscript. The content is solely the responsibility of the authors and does not necessarily represent the official views of the National Cancer Institute or the National Institute of Health. We are grateful to Theodore Witte and Drs. W. Elaine Hardman and Flavia De Carlo for critical review of the manuscript and to Ashley Gaing for technical assistance.

\section{Competing interests} interests.

The authors declare that they have no competing

\section{REFERENCES}

1. Cordon-Cardo, C., et al., Cooperative effects of p53 and pRB alterations in primary superficial bladder tumors. Cancer Res, 1997. 57(7): p. 1217-21.

2. Friend, S.H., et al., A human DNA segment with properties of the gene that predisposes to retinoblastoma and osteosarcoma. Nature, 1986. 323(6089): p. 643-6.

3. Toguchida, J. and T. Nakayama, Molecular genetics of sarcomas: applications to diagnoses and therapy. Cancer Sci, 2009. 100(9): p. 1573-80.

4. Williams, B.O., et al., Tumorigenic and developmental effects of combined germ-line mutations in $\mathrm{Rb}$ and $\mathrm{p} 53$. Cold Spring Harb Symp Quant Biol, 1994. 59: p. 449-57.

5. Mathew, R., et al., Alterations in $\mathrm{p} 53$ and $\mathrm{pRb}$ pathways and their prognostic significance in oesophageal cancer. Eur $\mathrm{J}$ Cancer, 2002. 38(6): p. 832-41.

6. Barton, C.M., et al., Abnormalities of the p53 tumour suppressor gene in human pancreatic cancer. Br J Cancer, 1991. 64(6): p. 1076-82.
7. Caldas, C., et al., Frequent somatic mutations and homozygous deletions of the p16 (MTS1) gene in pancreatic adenocarcinoma. Nat Genet, 1994. 8(1): p. $27-$ 32.

8. Laurie, N.A., et al., Inactivation of the p53 pathway in retinoblastoma. Nature, 2006. 444(7115): p. 61-6.

9. Yap, D.B., et al., mdm2: a bridge over the two tumour suppressors, p53 and Rb. Oncogene, 1999. 18(53): p. 76819.

10. Dong, Y., et al., Reduced expression of retinoblastoma gene product (pRB) and high expression of p53 are associated with poor prognosis in ovarian cancer. Int J Cancer, 1997. 74(4): p. 407-15.

11. Zhou, Z., et al., Synergy of p53 and Rb deficiency in a conditional mouse model for metastatic prostate cancer. Cancer Res, 2006. 66(16): p. 7889-98.

12. Yin, Y., et al., Differential regulation of $\mathrm{p} 21$ by p53 and $\mathrm{Rb}$ in cellular response to oxidative stress. Mol Carcinog, 1999. 24(1): p. 15-24.

13. Sherr, C.J. and F. McCormick, The RB and $\mathrm{p} 53$ pathways in cancer. Cancer Cell, 2002. 2(2): p. 103-12.

14. Polager, S. and D. Ginsberg, p53 and E2f: partners in life and death. Nat Rev Cancer, 2009. 9(10): p. 738-48.

15. Buckbinder, L., et al., The p53 tumor suppressor targets a novel regulator of $\mathrm{G}$ protein signaling. Proc Natl Acad Sci U S A, 1997. 94(15): p. 7868-72.

16. De Vries, L., et al., The regulator of $\mathrm{G}$ protein signaling family. Annu Rev Pharmacol Toxicol, 2000. 40: p. 235-71.

17. Berthebaud, M., et al., RGS16 is a negative regulator of SDF-1-CXCR4 signaling in megakaryocytes. Blood, 2005. 106(9): p. 2962-8.

18. Johnson, E.N., et al., RGS16 inhibits signalling through the G alpha 13-Rho axis. Nat Cell Biol, 2003. 5(12): p. 1095103.

19. Liang, G., et al., RGS16 inhibits breast cancer cell growth by mitigating phosphatidylinositol 3- kinase signaling. J Biol Chem, 2009. 284(32): p. 21719-27.

20. Teicher, B.A. and S.P. Fricker, CXCL12 (SDF-1)/CXCR4 pathway in cancer. Clin Cancer Res, 2010. 16(11): p. 2927 31.

21. Marchesi, F., et al., Increased survival, proliferation, and migration in metastatic human pancreatic tumor cells expressing functional CXCR4. Cancer Res, 2004. 64(22): p. 8420-7.

22. Ng, S.S.W., et al., Inhibition of phosphatidylinositide 3-kinase enhances gemcitabine-induced apoptosis in human pancreatic cancer cells. Cancer Res, 2000. 60(19): p. 5451-

23. Schlieman, M.G., et al., Incidence, mechanism and prognostic value of activated AKT in pancreas cancer. Br J Cancer, 2003. 89(11): p. 2110-5.

24. Osaki, M., M. Oshimura, and H. Ito, PI3K-Akt pathway: its functions and alterations in human cancer. Apoptosis, 2004. 9(6): p. 667-76 
25. Wiechec, E., J. Overgaard, and L.L. Hansen, A fragile site within the HPC1 region at 1q25.3 affecting RGS16, RGSL1, and RGSL2 in human breast carcinomas. Genes Chromosomes Cancer, 2008. 47(9): p. 766-80.

26. Kim, J.H., et al., RGS16 and FosB underexpressed in pancreatic cancer with lymph node metastasis promote tumor progression. Tumour Biol, 2010. 31(5): p. 541-8.

27. Mian, O.Y., et al., Management options in locally advanced pancreatic cancer. Curr Oncol Rep, 2014. 16(6): p. 388.

28. Hidalgo, M., Pancreatic cancer. N Engl J Med, 2010. 362(17): p. 1605-17.

29. Ghaneh, P., E. Costello, and J.P. Neoptolemos, Biology and management of pancreatic cancer. Postgrad Med J, 2008. 84(995): p. 478-97.

30. Itahana, K., et al., A role for p53 in maintaining and establishing the quiescence growth arrest in human cells. J Biol Chem, 2002. 277(20): p. 18206-14.

31. Marchesini, N., et al., Role for mammalian neutral sphingomyelinase 2 in confluence-induced growth arrest of MCF7 cells. J Biol Chem, 2004. 279(24): p. 25101-11.

32. Zhao, S., et al., Expression of oncogenic K-ras and loss of Smad4 cooperate to induce the expression of EGFR and to promote invasion of immortalized human pancreas ductal cells. Int J Cancer, 2010. 127(9): p. 2076-87.

33. Yamanaka, Y., et al., Coexpression of epidermal growth factor receptor and ligands in human pancreatic cancer is associated with enhanced tumor aggressiveness. Anticancer Res, 1993. 13(3): p. 565-9.

34. Ardito, C.M., et al., EGF receptor is required for KRASinduced pancreatic tumorigenesis. Cancer Cell, 2012. 22(3): p. 304-17.

35. Shinohara, H., et al., Retinoblastoma protein-initiated cellular growth arrest overcomes the ability of cotransfected wild-type p53 to induce apoptosis. Br J Cancer, 2000. 83(8): p. $1039-46$.

36. Ip, S.M., et al., pRb-expressing adenovirus Ad5-Rb attenuates the p53-induced apoptosis in cervical cancer cell lines. Eur J Cancer, 2001. 37(18): p. 2475-83.

37. Derenzini, M., et al., The p53-mediated sensitivity of cancer cells to chemotherapeutic agents is conditioned by the status of the retinoblastoma protein. J Pathol, 2009. 219(3): p. 373-82.

38. Spurgers, K.B., et al., Identification of cell cycle regulatory genes as principal targets of p53-mediated transcriptional repression. J Biol Chem, 2006. 281(35): p. 25134-42.

39. Ho, J. and S. Benchimol, Transcriptional repression mediated by the p53 tumour suppressor. Cell Death Differ, 2003. 10(4): p. 404-8.

40. Zhao, R., et al., Analysis of p53-regulated gene expression patterns using oligonucleotide arrays. Genes Dev, 2000. 14(8): p. 981-93.

41. Hammond, E.M., et al., Genome-wide analysis of p53 under hypoxic conditions. Mol Cell Biol, 2006. 26(9): p. 3492 504.
42. Kannan, K., et al., DNA microarrays identification of primary and secondary target genes regulated by $\mathrm{p} 53$. Oncogene, 2001. 20(18): p. 2225-34.

43. Chen, Y., D. Schlessinger, and R. Nagaraja, T antigen transformation reveals Tp53/RB-dependent route to PLAC1 transcription activation in primary fibroblasts. Oncogenesis, 2013. 2: p. e67.

44. Chen, H.Z., S.Y. Tsai, and G. Leone, Emerging roles of E2Fs in cancer: an exit from cell cycle control. Nat Rev Cancer, 2009. 9(11): p. 785-97.

45. Claudio, P.P., T. Tonini, and A. Giordano, The retinoblastoma family: twins or distant cousins? Genome Biol, 2002. 3(9): p. reviews3012.

46. Genovese, C., et al., Cell cycle control and beyond: emerging roles for the retinoblastoma gene family. Oncogene, 2006. 25(38): p. 5201-9.

47. Sun, H., et al., E2f binding-deficient Rb1 protein suppresses prostate tumor progression in vivo. Proc Natl Acad Sci U S A, 2011. 108(2): p. 704-9.

48. Sellers, W.R., et al., Stable binding to E2F is not required for the retinoblastoma protein to activate transcription, promote differentiation, and suppress tumor cell growth. Genes Dev, 1998. 12(1): p. 95-106.

49. Batsche, E., et al., Rb enhances p160/SRC coactivatordependent activity of nuclear receptors and hormone responsiveness. J Biol Chem, 2005. 280(20): p. 19746-56.

50. Osada, M., et al., A p53-type response element in the GDF15 promoter confers high specificity for $\mathrm{p} 53$ activation. Biochem Biophys Res Commun, 2007. 354(4): p. 913-8.

51. Rouault, J.P., et al., Identification of BTG2, an antiproliferative p53-dependent component of the DNA damage cellular response pathway. Nat Genet, 1996. 14(4): p. 482-6.

52. Taira, N., et al., Induction of amphiregulin by $\mathrm{p} 53$ promotes apoptosis via control of microRNA biogenesis in response to DNA damage. Proc Natl Acad Sci U S A, 2014. 111(2): p. 717-22.

53. Yoon, H., et al., Gene expression profiling of isogenic cells with different TP53 gene dosage reveals numerous genes that are affected by TP53 dosage and identifies CSPG2 as a direct target of p53. Proc Natl Acad Sci U S A, 2002. 99(24): p. 15632-7.

54. Hoeferlin, L.A., et al., Folate stress induces apoptosis via p53-dependent de novo ceramide synthesis and upregulation of ceramide synthase 6. J Biol Chem, 2013. 288(18): p. 12880-90.

55. Jeong, B.S., et al., Differential levels of transcription of p53-regulated genes by the arginine/proline polymorphism: p53 with arginine at codon 72 favors apoptosis. FASEB J, 2010. 24(5): p. 1347-53.

56. Sheikh, M.S., et al., The antiapoptotic decoy receptor TRID/ TRAIL-R3 is a p53-regulated DNA damage-inducible gene that is overexpressed in primary tumors of the gastrointestinal tract. Oncogene, 1999. 18(28): p. 4153-9. 
57. Ohashi, T., et al., AKR1B10, a transcriptional target of $\mathrm{p} 53$, is downregulated in colorectal cancers associated with poor prognosis. Mol Cancer Res, 2013. 11(12): p. 1554-63.

58. Kudoh, T., et al., D4S234E, a novel p53-responsive gene, induces apoptosis in response to DNA damage. Exp Cell Res, 2010. 316(17): p. 2849-58.

59. Jiang, H., et al., pRB and p107 have distinct effects when expressed in pRB-deficient tumor cells at physiologically relevant levels. Oncogene, 2000. 19(34): p. 3878-87.

60. Vernell, R., K. Helin, and H. Muller, Identification of target genes of the p16INK4A-pRB-E2F pathway. J Biol Chem, 2003. 278(46): p. 46124-37.

61. Bourgo, R.J., et al., RB restricts DNA damage-initiated tumorigenesis through an LXCXE- dependent mechanism of transcriptional control. Mol Cell, 2011. 43(4): p. 663-72.

62. Daoud, S.S., et al., Impact of p53 knockout and topotecan treatment on gene expression profiles in human colon carcinoma cells: a pharmacogenomic study. Cancer Res, 2003. 63(11): p. 2782-93.

63. Dorsam, R.T. and J.S. Gutkind, G-protein-coupled receptors and cancer. Nat Rev Cancer, 2007. 7(2): p. 79-94.

64. Jang, S. and M.B. Atkins, Treatment of BRAF-mutant melanoma: the role of vemurafenib and other therapies. Clin Pharmacol Ther, 2014. 95(1): p. 24-31.

65. Davidsson, J., et al., Tiling resolution array comparative genomic hybridization, expression and methylation analyses of dup(1q) in Burkitt lymphomas and pediatric high hyperdiploid acute lymphoblastic leukemias reveal clustered near-centromeric breakpoints and overexpression of genes in 1q22-32.3. Hum Mol Genet, 2007. 16(18): p. 2215-25.

66. Miyoshi, N., et al., RGS16 is a marker for prognosis in colorectal cancer. Ann Surg Oncol, 2009. 16(12): p. 350714.

67. Liu, T., et al., The retinoid anticancer signal: mechanisms of target gene regulation. Br J Cancer, 2005. 93(3): p. 310-8.

68. Vasilatos, S.N., et al., Crosstalk between lysine-specific demethylase 1 (LSD1) and histone deacetylases mediates antineoplastic efficacy of HDAC inhibitors in human breast cancer cells. Carcinogenesis, 2013. 34(6): p. 1196-207.

69. Lippert, E., et al., Role of regulator of $\mathrm{G}$ protein signaling 16 in inflammation-induced $\mathrm{T}$ lymphocyte migration and activation. J Immunol, 2003. 171(3): p. 1542-55.

70. Shankar, S.P., et al., RGS16 attenuates pulmonary Th2/ Th17 inflammatory responses. J Immunol, 2012. 188(12): p. 6347-56.

71. Kusama, T., et al., Inhibition of epidermal growth factorinduced RhoA translocation and invasion of human pancreatic cancer cells by 3-hydroxy-3-methylglutarylcoenzyme a reductase inhibitors. Cancer Res, 2001. 61(12): p. 4885-91.

72. Roger, L., G. Gadea, and P. Roux, Control of cell migration: a tumour suppressor function for p53? Biol Cell, 2006. 98(3): p. 141-52.
73. Liu, J., et al., Wild-type p53 inhibits nuclear factor-kappaBinduced matrix metalloproteinase-9 promoter activation: implications for soft tissue sarcoma growth and metastasis. Mol Cancer Res, 2006. 4(11): p. 803-10.

74. Sun, Y., et al., Human metalloproteinase-1 (collagenase-1) is a tumor suppressor protein p53 target gene. Ann N Y Acad Sci, 1999. 878: p. 638-41.

75. Sun, Y., et al., p53 down-regulates human matrix metalloproteinase-1 (Collagenase-1) gene expression. J Biol Chem, 1999. 274(17): p. 11535-40.

76. Zhu, H., et al., A role for p53 in the regulation of extracellular matrix metalloproteinase inducer in human cancer cells. Cancer Biol Ther, 2009. 8(18): p. 1722-8.

77. Andrusiak, M.G., et al., $\mathrm{Rb} / \mathrm{E} 2 \mathrm{~F}$ regulates expression of neogenin during neuronal migration. Mol Cell Biol, 2011. 31(2): p. 238-47.

78. Kim, K.J., et al., Rb suppresses collective invasion, circulation and metastasis of breast cancer cells in CD44dependent manner. PLoS One, 2013. 8(12): p. e80590.

79. Johnson, J.L., et al., Regulation of matrix metalloproteinase genes by E2F transcription factors: Rb-Raf-1 interaction as a novel target for metastatic disease. Cancer Res, 2012. 72(2): p. 516-26.

80. Sethakorn, N., D.M. Yau, and N.O. Dulin, Non-canonical functions of RGS proteins. Cell Signal, 2010. 22(9): p. 1274-81.

81. Su, Z.Z., et al., The cancer growth suppressor gene mda-7 selectively induces apoptosis in human breast cancer cells and inhibits tumor growth in nude mice. Proc Natl Acad Sci U S A, 1998. 95(24): p. 14400-5.

82. Greco, A., et al., Eradication of therapy-resistant human prostate tumors using an ultrasound- guided site-specific cancer terminator virus delivery approach. Mol Ther, 2010. 18(2): p. 295-306.

83. Nande, R., et al., Targeting a newly established spontaneous feline fibrosarcoma cell line by gene transfer. PLoS One, 2012. 7(5): p. e37743.

84. Tusher, V.G., R. Tibshirani, and G. Chu, Significance analysis of microarrays applied to the ionizing radiation response. Proc Natl Acad Sci U S A, 2001. 98(9): p. 511621.

85. Livak, K.J. and T.D. Schmittgen, Analysis of relative gene expression data using real-time quantitative PCR and the 2(-Delta Delta C(T)) Method. Methods, 2001. 25(4): p. 4028 .

86. Lo, H.W., et al., Epidermal growth factor receptor cooperates with signal transducer and activator of transcription 3 to induce epithelial-mesenchymal transition in cancer cells via up- regulation of TWIST gene expression. Cancer Res, 2007. 67(19): p. 9066-76.

87. Dittmar, T., et al., Induction of cancer cell migration by epidermal growth factor is initiated by specific phosphorylation of tyrosine 1248 of c-erbB-2 receptor via EGFR. FASEB J, 2002. 16(13): p. 1823-5. 
88. Giehl, K., et al., Growth factor-dependent activation of the Ras-Raf-MEK-MAPK pathway in the human pancreatic carcinoma cell line PANC-1 carrying activated K-ras: implications for cell proliferation and cell migration. Oncogene, 2000. 19(25): p. 2930-42.

89. Deer, E.L., et al., Phenotype and genotype of pancreatic cancer cell lines. Pancreas, 2010. 39(4): p. 425-35.

90. Ali, S., et al., Simultaneous targeting of the epidermal growth factor receptor and cyclooxygenase-2 pathways for pancreatic cancer therapy. Mol Cancer Ther, 2005. 4(12): p. 1943-51. 